\title{
RARE-EARTH PERMANENT MAGNET IN MAGNETIC SYSTEM OF ELECTRON ACCELERATOR WITH THE ENERGY OF $10 \mathrm{MeV}$
}

\author{
V.A. Bovda, A.M. Bovda, I.S. Guk, S.S. Kandybey, S.G. Kononenko, V.N. Lyashchenko, \\ A.O. Mytsykov, L.V. Onischenko \\ National Science Center "Kharkov Institute of Physics and Technology”, Kharkov, Ukraine \\ E-mail: bovda@kipt.kharkov.ua
}

The radiation resistance of Sm-Co and Nd-Fe-B magnets under $10 \mathrm{MeV}$ electron beam was studied. The simulation and design of a magnetic system for electron beam analysis of a technological accelerator for energy up to $10 \mathrm{MeV}$ was carried out. The key component of magnetic system was $\mathrm{Sm}_{2} \mathrm{Co}_{17}$ magnets with the size of $30 \times 24 \times 12 \mathrm{~mm}$. The maximum magnetic field in the magnetic system was $0.3 \mathrm{~T}$.

PACS: $29.30 . \mathrm{Kv}$

\section{INTRODUCTION}

There is a considerable interest in the magnetic systems on the base of rare-earth permanent magnets for use in special accelerators such as medical and technological accelerators, microtrons, liner colliders and etc [1-5]. The creation of each such device is associated with the need to take into account the parameters of accelerators and the features of their operation. The key component of the accelerating unit is permanent magnets. The magnetic performance, time and thermal stability of the magnetic materials under irradiation play crucial role for the steady operational parameters.

Linear accelerator LU-10 [6] in the NSC KIPT has been used for many years for technological radiation treatment of materials. Now, significant upgrade of all the accelerator systems is performed. The main beam parameter of this accelerator [7] after system upgrading - maximum energy must be near $9.44 \mathrm{MeV}$. The upgrading beam parameters were used in selecting the basic requirements for a magnetic system aimed at measuring the energy of the accelerator beam [8, 9]. According to the simulation and experimental measurements, the design of the magnet should provide a field of about $0.3 \mathrm{~T}$ in a gap of $2.5 \mathrm{~cm}$.

The choice of magnetic material for use in a magnetic system has been made. The paper also presents the results of the development of the design and experimental details of the magnetic characteristics of magnetic system.

\section{THE CHOICE OF MAGNET MATERIAL}

One of the practical aspects of permanent magnets using in the technological accelerators is the high radiation background. Thus, magnetic materials should preserve magnetic performance under high radiation doses induced by electron beam and bremsstrahlung. Despite an extensive literature on radiation stability of Sm-Co and $\mathrm{Nd}-\mathrm{Fe}-\mathrm{B}$ magnets under electron irradiation with energy from $8 \mathrm{GeV}$ to $10 \mathrm{MeV}$ and gamma-radiation [10-23], the selection of appropriate magnetic material can be described relatively unambiguously. Accordingly, experimental study of magnetic losses of Sm-Co and $\mathrm{Nd}-\mathrm{Fe}-\mathrm{B}$ magnets under direct electron beam irradiation with the energy of $10 \mathrm{MeV}$ and bremsstrahlung were carried out [24, 25].

Permanent magnets were produced by powder metallurgy [26]. Magnetic samples were magnetized to the technical saturation in the magnetic field of $3.5 \mathrm{~T}$. Typi- cal size of rectangular magnets was $30 \times 24 \times 12 \mathrm{~mm}$. $\mathrm{Nd}-\mathrm{Fe}-\mathrm{B}$ magnets were covered with $\mathrm{Ni}$ coating.

Samples were irradiated by electron beam with energy of $10 \mathrm{MeV}$ on the linear technological accelerator KUT-1 [27]. The axis of accelerator was located vertically. The electron beam yield was from top to down. Electron beam passed to the air through the titanium foil. In the experiment, the south pole of Nd-Fe-B magnets $(30 \times 24 \mathrm{~mm}$ side $)$ underwent electron irradiation. The deviation of electron beam density was about $10 \%$ above the sample's surface. During the electron irradiation, magnets were cooled by the water. The temperature of the coolant water was not less than $40{ }^{\circ} \mathrm{C}$.

Four (4) Nd-Fe-B and four (4) Sm-Co magnets were used in experiments. The following designation was used for both types of magnets. Samples 1 and 2 were irradiated continuously for 20 hours. Electron beam went directly to the surface of sample 1 . The absorbed dose for the sample 1 was 16 Grad (the total electron flux was of about $1.4 \cdot 10^{17}$ electrons $/ \mathrm{cm}^{2}$ ). Sample 2 was irradiated simultaneously with the sample 1, but sample 2 was set far from the electron beam at the distance of $40 \mathrm{~mm}$. Sample 3 was irradiated for 20 hours with 24 intervals. The total absorbed dose for the sample 3 was 160 Grad. Sample 4 was not irradiated and it was used as the reference sample for the measurements.

It was revealed that $\mathrm{Nd}-\mathrm{Fe}-\mathrm{B}$ magnets had a small amount of ${ }^{147} \mathrm{Nd}$ unstable isotope. It is the result of ${ }^{148} \mathrm{Nd}(\gamma, \mathrm{n}){ }^{147} \mathrm{Nd}$ reaction with the energy threshold of $7.3 \mathrm{MeV}$ and half lifetime of 10.98 days. The radiation spectrum of Sm-Co magnets was characterized by the ${ }^{153} \mathrm{Sm}$ isotope produced by ${ }^{154} \mathrm{Sm}(\gamma, \mathrm{n}){ }^{153} \mathrm{Sm}$ reaction under gamma-radiation of electron bremsstrahlung. The isotope half lifetime is $\mathbf{4 6 . 2 8 4}$ hours. Thus, the activity of the magnets after the irradiation was within normal range. The latter allows normal operation of the devices with Nd-Fe-B and Sm-Co magnets in accelerators with the energy up to $10 \mathrm{MeV}$.

\section{MAGNETIC MEASUREMENTS}

The measurements of the normal z-component of magnetic flux were performed using Hall probe line (HPL) [24]. Hall probes were mounted into the cupper matrix for temperature compensation. The distance between Hall probes on the HPL was about $6 \mathrm{~mm}$. The accuracy of measurements was about $0.03 \%$.

The sample was passed transversely to the HPL. The distance between magnets and HPL was $3.05 \mathrm{~mm}$. 
Magnets passed over the HPL with the step from 3 to $5 \mathrm{~mm}$. The precision of magnet's position was about $1 \mu \mathrm{m}$. The initial position of the sample within HLP was fixed by stoppers. HLP measurements were performed on the both sides of the magnet (north pole and south pole).

3D quadratic interpolation can be used to estimate approximation of magnetic field gradients along the plane of a magnet. The approximation was done using the measured HPL data. The interpolation area was set by the distance between outermost probes of HPL and $\mathrm{x}-\mathrm{y}$ scanning area. The scanning area was precisely determined by the sample coordinate system. Fig. 1 shows the interpolation results for the HPL collected data for non-treated Nd-Fe-B sample 1.

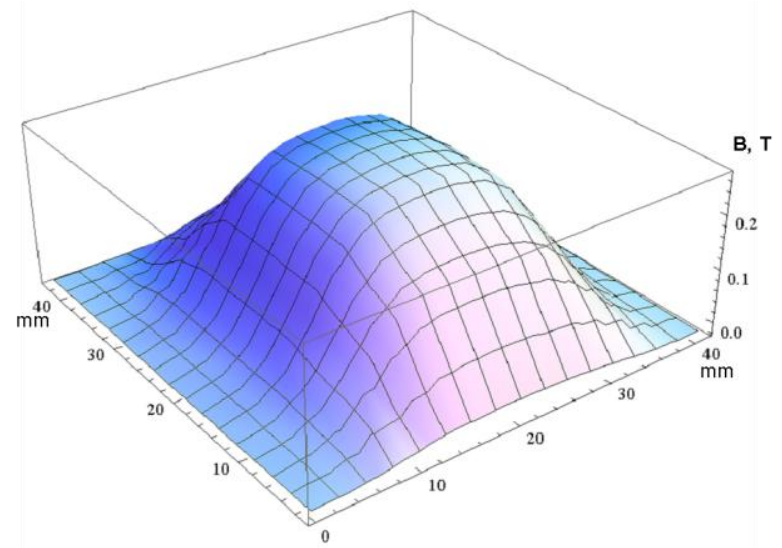

Fig. 1. Interpolation of the experimental data for the $\mathrm{Nd}-\mathrm{Fe}$-B magnet (sample 1) before irradiation

In order to estimate the changes in magnetic flux, the integral of the 3D interpolation normal component of magnetic flux was used. Calculated S-parameter measured in arbitrary units was chosen as integrated z-component of magnetic flux. The S-parameter is calculated within the $x-y$ plane of the magnet. The relative error for S-parameter is about $0.5 \%$ within HPL boundaries.

The S-parameters of Nd-Fe-B magnets (north pole) before electron irradiation are shown in the Tabl. 1. It was revealed that $\mathrm{S}$-parameter for both poles (south and north) coincided within the experiment accuracy.

Table 1

$\mathrm{S}$-parameter (integrated z-component of magnetic flux) of Nd-Fe-B magnets before and after electron irradiation

\begin{tabular}{|c|c|c|c|}
\hline \multirow{3}{*}{ Sample } & \multicolumn{3}{|c|}{ S, a.u. } \\
\cline { 2 - 4 } & Initial & \multicolumn{2}{|c|}{$e$-irradiated } \\
\cline { 2 - 4 } & north pole* & north pole & south pole \\
\hline 1 & 175.763 & 162.356 & 160.2 \\
\hline 2 & 179.556 & 178.526 & - \\
\hline 3 & 176.357 & 126.556 & - \\
\hline 4 & 175.452 & - & - \\
\hline
\end{tabular}

*North and south pole coincides within relative error.

The interpolations of magnetic field distribution of the sample 1 (north pole and south pole) after electron irradiation are depicted in Figs. 2 and 3, accordingly. One can see that $\mathrm{S}$ value was decreased to 162.356 and 160.2 .

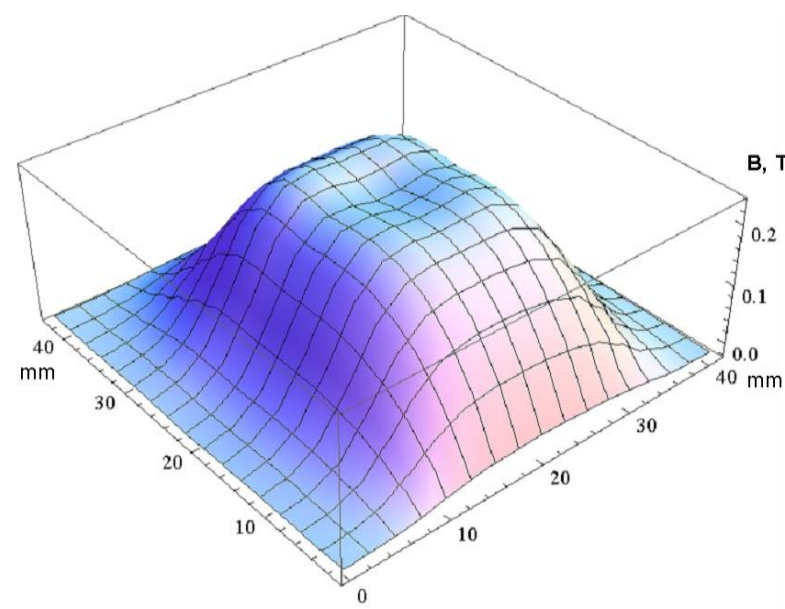

Fig. 2. Interpolation of the experimental data for the north pole of $\mathrm{Nd}-\mathrm{Fe}-\mathrm{B}$ magnet (sample 1) after irradiation. Absorbed dose of $16 \mathrm{Grad}$

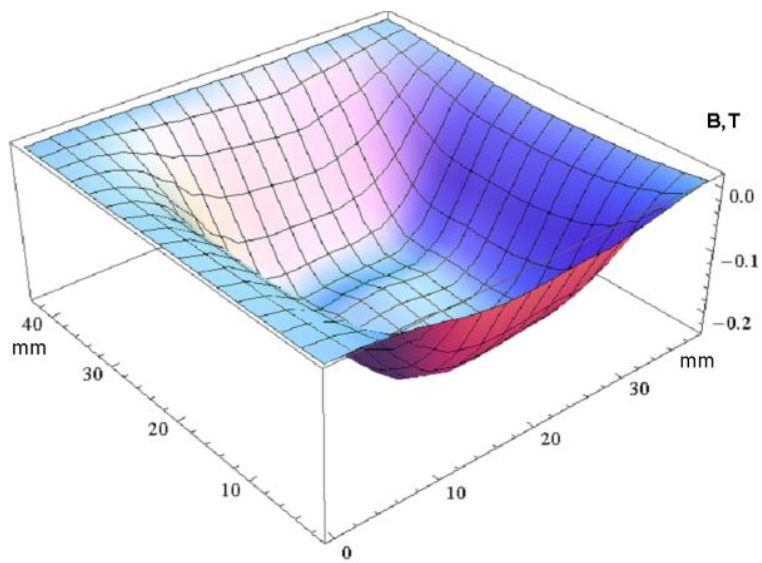

Fig. 3. Interpolation of the experimental data for the south pole of $\mathrm{Nd}-\mathrm{Fe}-\mathrm{B}$ magnet (sample 1) after irradiation. Absorbed dose of $16 \mathrm{Grad}$

As can be seen in Figs. 2 and 3, magnetic field distribution and S-parameters coincided for both poles of the magnet (sample 1) within the accuracy of measurements.

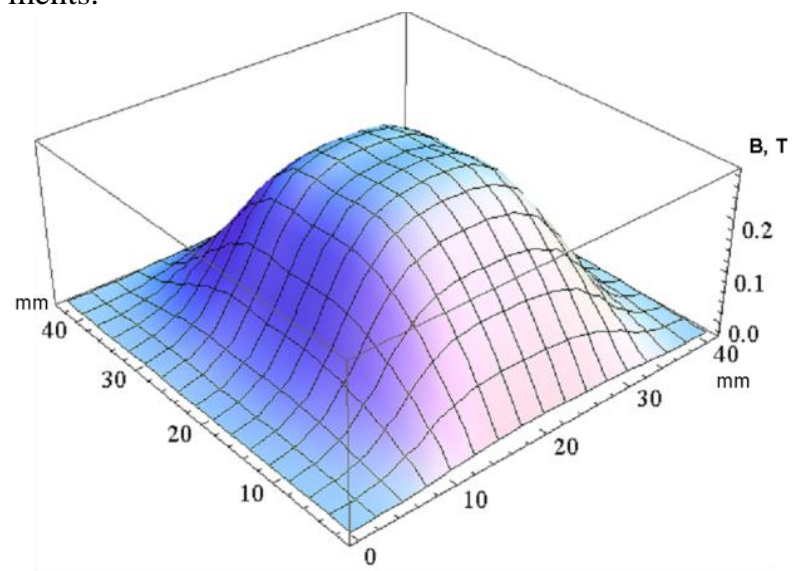

Fig. 4. Interpolation of the experimental data for the north pole of $\mathrm{Nd}-\mathrm{Fe}$-B magnet (sample 2) after bremsstrahlung irradiation. Absorbed dose of $16 \mathrm{Grad}$

The magnetic field distribution for the sample 2 after bremsstrahlung irradiation was the same as before irradiation (Fig. 4) and the S-parameter of 178.526 was practically the same.

The substantial changes in the magnetic field distribution after irradiation were observed for sample 3 
(Fig. 5). The S-parameter for the sample 3 was decreased to 126.556 . It should be noticed that reduction of S-parameter was not proportional to the absorbed dose.

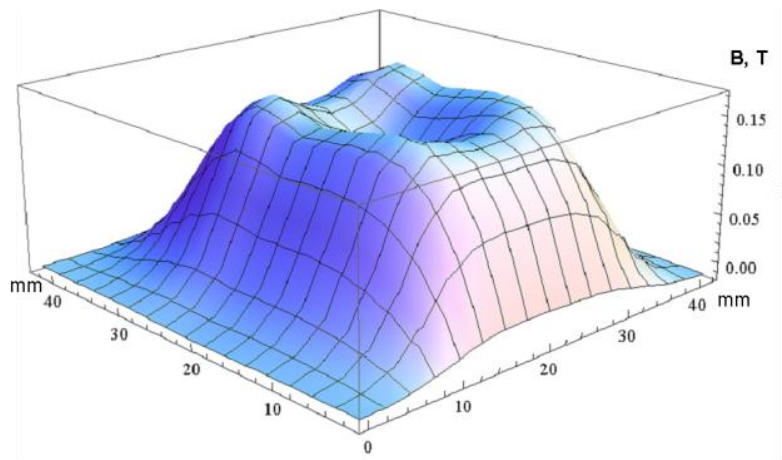

Fig. 5. Interpolation of the experimental data for the north pole of $\mathrm{Nd}-\mathrm{Fe}-\mathrm{B}$ magnet (sample 3) after irradiation. Absorbed dose of $160 \mathrm{Grad}$

For the reference sample 4, the magnetic field distribution measurements after the end of the measurement cycle on the irradiated samples showed a coincidence with the distributions obtained before irradiation.

The similar magnetic measurements were done for Sm-Co magnets. The S-parameters are as following the south pole for the sample 1 is 151.94 , for the sample 2 is 149.007, for the sample 3 is 152.326 , for the sample 4 is 152.519 (Tabl. 2). The S-parameters of north pole were the same as for the south pole within experiment accuracy.

The interpolation of the magnetic field distribution of Sm-Co magnet (sample 1) before irradiation is shown in Figs. 6 and 7.

Table 2

S-parameter (integrated z-component of magnetic flux) of Sm-Co magnets before and after electron irradiation

\begin{tabular}{|c|l|c|c|}
\hline \multirow{3}{*}{ Sample } & \multicolumn{3}{|c|}{ S, a.u. } \\
\cline { 2 - 4 } & Initial & \multicolumn{2}{|c|}{$e$-irradiated } \\
\cline { 2 - 4 } & South pole* & north pole & south pole \\
\hline 1 & 151.94 & - & - \\
\hline 2 & 149.007 & 148.397 & 149.727 \\
\hline 3 & 152.326 & 149.714 & 150.065 \\
\hline 4 & 152.519 & 152.496 & 155.135 \\
\hline
\end{tabular}

*North and south pole coincides within relative error.

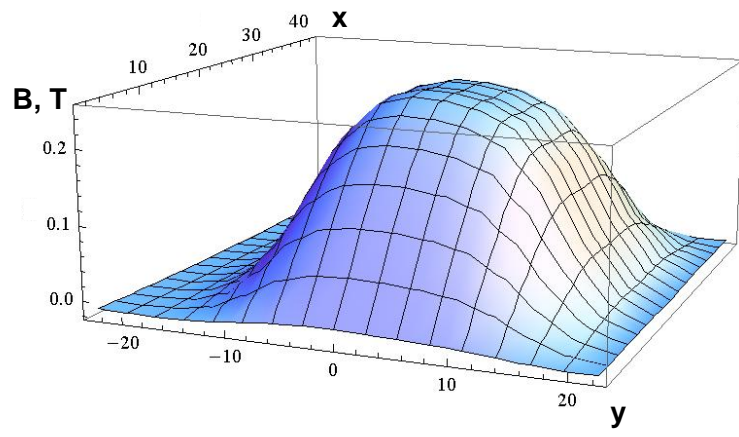

Fig. 6. Interpolation of the experimental data for the south pole of Sm-Co magnet (sample 1) before irradiation

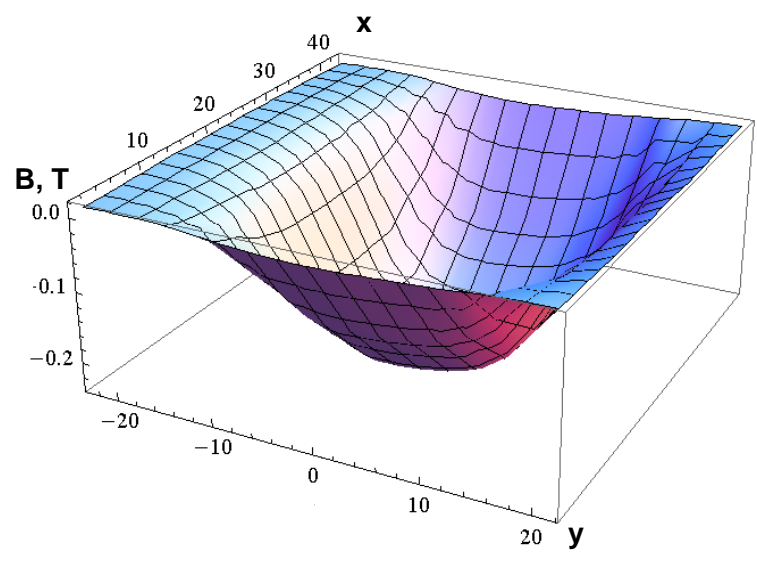

Fig. 7. Interpolation of the experimental data for the north pole of Sm-Co magnet (sample 1) before irradiation

The distribution of the magnetic field of Sm-Co magnet (sample 1) left unchanged after irradiation (Fig. 8)

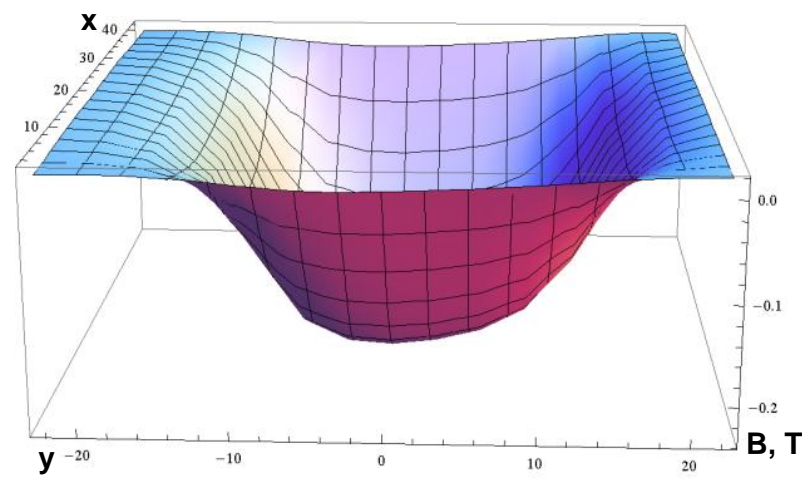

Fig. 8. Interpolation of the experimental data for the north pole of Sm-Co magnet (sample 1) after irradiation. Absorbed dose of $16 \mathrm{Grad}$

It was revealed that the absorbed dose of $160 \mathrm{Grad}$ for the sample 3 did not change the initial magnetic field distribution around the magnet. The S-parameter of sample 2 was 148.397 and 149.727 , for the sample 3 was 149.714 and 150.065 for the north and south poles respectively. The magnetic field distributions of reference samples were not changed during experiments. Despite high absorption doses, Sm-Co magnets (sample 2 and sample 3) preserved their magnetic performance. The S-parameter of untreated Sm-Co magnet (sample 4) was 152.496 and 155.135 , correspondingly.

Thus, it was shown the advantage of using Sm-Co magnets, because their magnetic properties did not change under direct irradiation with an electron beam and bremsstrahlung.

In addition, $\mathrm{Sm}_{2} \mathrm{Co}_{17}$ magnets have better magnetic characteristics under critical conditions as the device should remain stable. Such conditions can often arise when magnets are used on technological electron accelerators. In the case of operation under high temperatures and aggressive conditions, $\mathrm{Sm}_{2} \mathrm{Co}_{17}$ alloy have certain advantages over devices made of $\mathrm{Nd}-\mathrm{Fe}-\mathrm{B}$ alloy. The Curie temperature of the $\mathrm{Sm}_{2} \mathrm{Co}_{17}$ alloy is $T_{\mathrm{c}}=825{ }^{0} \mathrm{C}$. The maximum operating temperature of the Sm-Co magnets reaches $T_{\mathrm{w}}=350{ }^{0} \mathrm{C}$. The Curie temperature of 
the Nd-Fe-B magnet is $T_{\mathrm{c}}=312{ }^{\circ} \mathrm{C}$. Thus, under real experimental conditions the operating temperatures for this alloy should not exceed $T_{\mathrm{w}}=180{ }^{\circ} \mathrm{C}$.

The temperature stability of $\mathrm{Nd}-\mathrm{Fe}-\mathrm{B}$ magnets is smaller than that of Sm-Co magnets. The temperature coefficient of magnetic induction $\left(\mathrm{B}_{\mathrm{r}}\right)$ of Nd-Fe-B magnets varies from 0.07 to $0.13 \% / \mathrm{C}$, in contrast to $0.035 \% /{ }^{0} \mathrm{C}$ in $\mathrm{Sm}-\mathrm{Co}$ magnets. In addition, Sm-Co magnets are less prone to corrosion than neodymium magnets, and usually do not require coating. Hence, Sm-Co magnets were chosen for the development of a magnet system for electron accelerator.

\section{MAGNETIC SYSTEM DESIGN}

To assess the parameters of magnetic system, the simulation of beam travel at the output of the accelerator was carried out. The parameters of the beam and magnetic field inside magnetic system were fixed. The typical size of Sm-Co magnets for the design of magnetic systems was $30 \times 24 \times 12 \mathrm{~mm}$. The distance between Sm-Co magnets was $25 \mathrm{~mm}$. The typical magnetic field in the mid-plane of the magnetic system was about $0.3 \mathrm{~T}$. This peak magnetic field of $0.3 \mathrm{~T}$ was used for the simulation of beam travel. Hence, the simulation allowed designing the construction of magnetic system.

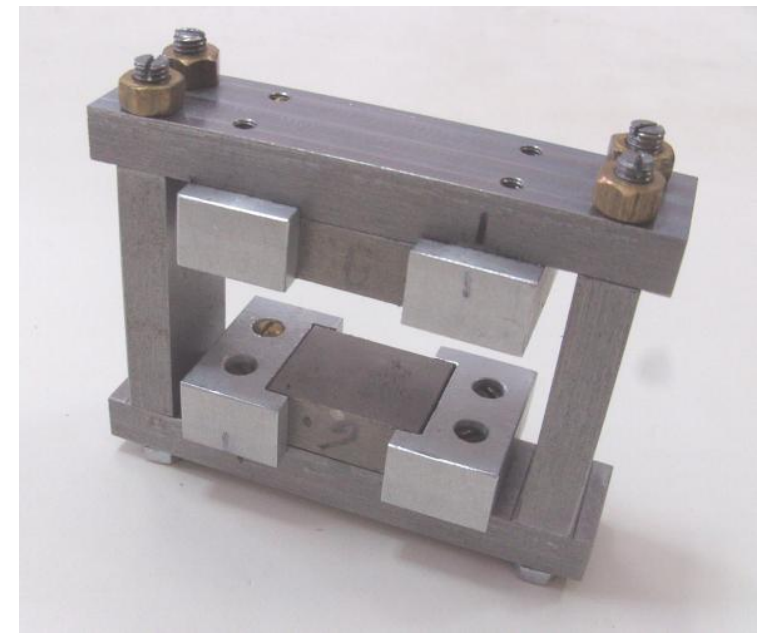

Fig. 9. Magnetic system for electron accelerator

Fig. 9 shows the magnetic system which was designed and constructed according simulation experiments. Outside dimensions of the magnetic circuit were $90 \times 73 \times 24 \mathrm{~mm}$. The magnetic circuit was made of soft magnetic steel. Sm-Co magnets were fixed to the bar by aluminum clamps. The tolerance and machining of parts were of $5 \mu \mathrm{m}$. The upper bar was designed portable to facilitate the dismantling of the magnetic system and the flange of accelerator during the measuring mode or adjustment accelerator energy procedure. The design of the magnetic system provides the dispersion of magnetic field in the both horizontal and vertical directions.

The distribution of magnetic field in the magnetic system was carried out by abovementioned HPL method. Fig. 10 shows the experimental plot of HPL data. The mid-plane scans in the gap of magnetic system on the base of Sm-Co magnets are shown in Fig. 11. It was found that peak magnetic field in the gap of magnetic system was $0.331103 \mathrm{~T}$. The effective length along the central line of beam track was $-33.533 \mathrm{~mm}$. The rotation angle of electron beam with the energy of $10 \mathrm{MeV}$ was $0.31 \mathrm{rad}$. The estimation of the rotation angle was done according to the simulation of electron beam motion.

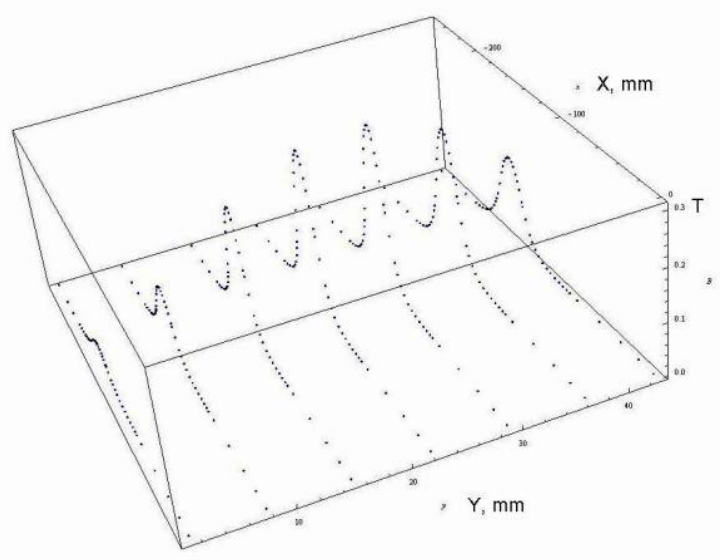

Fig. 10. The distribution of magnetic field of magnetic system on the base of Sm-Co magnets. Experimental HPL plot

The deviation of magnetic field in the gap of magnetic system was investigated under various regimes as opening and closing circuit, and the reconfiguration of the upper bar. Fig. 12 shows the measurements of seven Hall probes in the gap of magnetic system during 10 cycles of opening and closing circuit for $1000 \mathrm{~s}$.

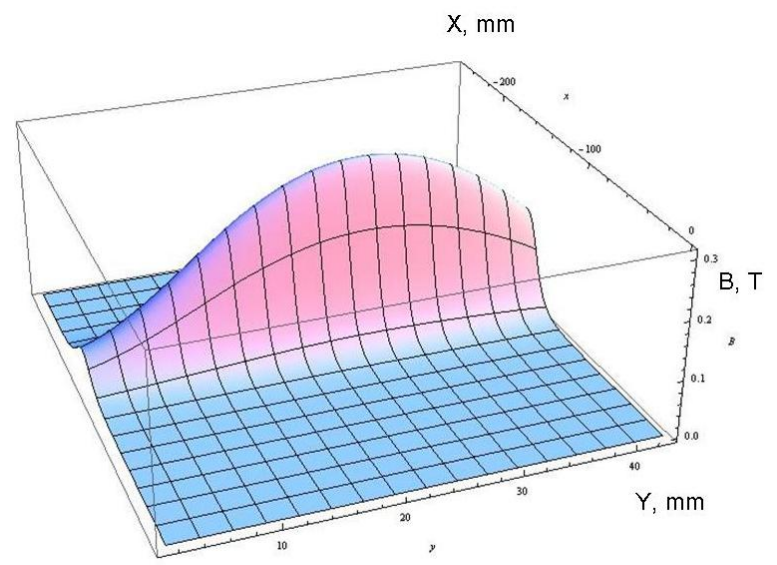

Fig. 11. Magnetic field distribution in the mid-plane of gap of magnetic system on the base of Sm-Co magnets (interpolation of HPL data)

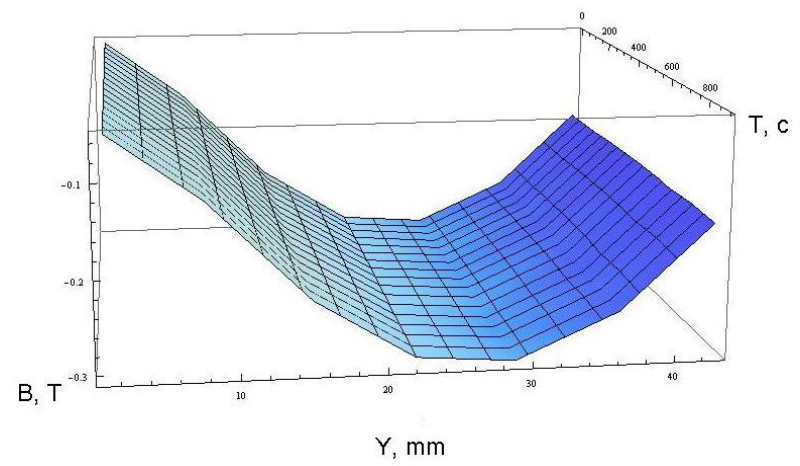

Fig. 12. The distribution of magnetic field in the magnetic system after one cycle of opening/closing circuit 


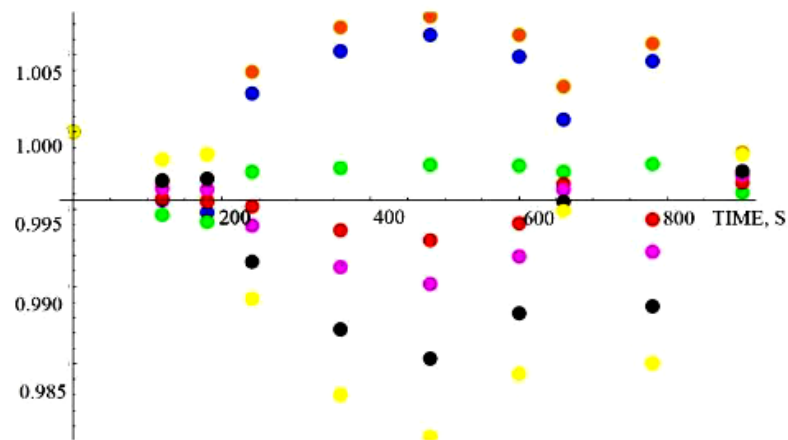

Fig. 13. The change of magnetic field (Hall probe data) after each cycle of closing and opening circuit

The relative change of the magnetic field at the measurement points is shown in Fig. 13. Hall probes located at the centre of the magnetic system (green, red and pink points) showed magnetic field variation about $0.5 \%$ after closing circuit.

\section{CONCLUSIONS}

In summary, it was revealed that Sm-Co magnets had advantage in preserving magnetic performance under high electron irradiation and bremsstrahlung. The optimal design of magnetic system for particular electron accelerator with the energy of $10 \mathrm{MeV}$ was developed. The measured parameters of the magnetic system agreed with the simulation experiment.

\section{REFERENCES}

1. V.I. Shvedunov et al. A $70 \mathrm{MeV}$ Race-Track Microtron // Nucl. Instr. Meth. 2005, v. 550, N 1-2, p. 3953.

2. David J. McLaughlin et al. Permanent-magnet energy spectrometer for electron beams from radiotherapy accelerators // Medical Physics. 2015, v. 42, N 9, p. 5517-5529.

3. F. Bødker. Permanent magnets in accelerators can save energy, space and cost // Proc. of IPAC2013, Shanghai, China, p. 3511-3513.

4. Alex Bainbridge, Ben Shepherd, Norbert Collomb, Jim Clarke, Michele Modena. The ZEPTO project: Tuneable permanent magnets for the next generation of high energy accelerators // Proc. 25th International Conference on Magnet Technology, Amsterdam, 30th August 2017. TalkID\#448, session Wed-Mo-Or19.

5. A.M. Bovda, I.S. Guk, A.N. Dovbnya, S.G. Kononenko, V.N. Lyashchenko, A.O. Mytsykov. Dipole magnet with a constant field for the accelerator "EPOS" // Problems of Atomic Science and Technology. Series "Nuclear Physics Investigations" (100). 2015, N 6, p. 13-17.

6. V.I. Beloglasov, A.I. Zykov, E.S. Zlunitsyn, G.D. Kramskoi, G.L. Fursov. An electron linac producing beam power up to $15 \mathrm{~kW} / /$ Proceedings of the 1996 EPAC. 1996, v. 1, p. 798-800.

7. N.I. Ayzatskiy et al. Accelerating system of the technological electron accelerator // Problems of Atomic Science and Technology. Series "Nuclear Physics Investigations" (80). 2012, N 4, p. 45-49.

8. A. Dovbnya, I. Guk, S. Kononenko, A. Tarasenko. Beam transport system selection on the accelerator LU-10 // Problems of Atomic Science and Technology.
Series "Nuclear Physics Investigations" (88). 2013, N 6, p. 57-61.

9. I.S. Guk, S.G. Kononenko, V.N. Lyashchenko, A.O. Mytsykov. Choice of parameters of the analyzing magnet for technological electron accelerator LU-10M // Problems of Atomic Science and Technology. Series "Nuclear Physics Investigations" (112). 2017, N 6, p. 24-27.

10. S. Okuda, K. Ohashi, N. Kobayashi. Effects of electron beam and y-ray irradiation on the magnetic flux of Nd-Fe-B and Sm-Co permanent magnets // Nucl. Instr. Meth. 1994, v. B94, p. 227-230.

11. H.B. Luna et al. Bremsstrahlung radiation effects in rare earth permanent magnets // Nucl. Instr. Meth. 1989, v. 285(1), p. 349-354.

12. J. Alderman et al. Measurement of radiationinduced demagnetization of $\mathrm{NdFeB}$ permanent magnets // Nucl. Instr. Meth. 2002, v. 481(1-3), p. 1-3.

13. A.N. Dovbnya et al. Study on radiation resistance of permanent $\mathrm{Nd}-\mathrm{Fe}-\mathrm{B}$-base magnets under continuous radiation conditions // Problems of Atomic Science and Technology. Series "Nuclear Physics Investigations". 1999, N 3(34), p. 48-49.

14. T. Bizen et al. Demagnetization of undulator magnets irradiated high energy electrons // Nucl. Instr. Meth. 2001, v. 467, p. 185-189.

15. T. Bizen et al. High-energy electron irradiation of NdFeB permanent magnets: Dependence of radiation damage on the electron energy // Nucl. Instr. Meth. 2007, v. 574(3), p. 401-406.

16. R. Qiu et al. Radiation damage of Nd2Fe14B permanent magnets at $2.5 \mathrm{GeV}$ electron accelerator // Nucl. Instr. Meth. 2008, v. 594(2), p. 111-118.

17. R.S. Gao et al. Study of $\gamma$-ray irradiation effect on permanent magnets // J. Appl. Phys. 2008, v. 103, p. $103-105$.

18. T. Ikeda and S. Okuda. Magnetic flux loss of the permanent magnets used for the wigglers of FELs by the irradiation with high-energy electrons or X-rays // Nucl. Instr. Meth. 1998, v. 407(1-3), p. 439-442.

19. N. Simos et al. An experimental study of radiation-induced demagnetization of insertion device permanent magnets // Proc. EPAC 2008, Genoa, Italy, 2008, p. 2112-2114.

20. P. Vagin, O. Bilani, A. Schöps, S. Tripathi, T. Vielitz, M. Tischer. Radiation damage of undulators at PETRA III // Proc. IPAC2014, Dresden, Germany, 2014, p. 2019-2021.

21. Rui Qiu, Hee-Seock Lee, Junli Li, Tae-Yeong Koo, T. Bizen \& Qiyong Fan. Demagnetization of NdFe-B permanent magnet at $2.5 \mathrm{GeV}$ electron accelerator // Journal of Nuclear Science and Technology. 2008, v. 45 , p. 46-49.

22. Y. Asano, T. Bizen, X.-M. Maréchal. Analyses of the factors for the demagnetization of permanent magnets caused by high - energy electron irradiation // Journal of Synchrotron irradiation. 2009, v. 16 p. 317324.

23. T. Bizen. Brief review of the approaches to elucidate the mechanism of the radiation-induced demagnetization // Proc. ERL2011, Tsukuba, Japan, 2011, p. 121-126. 
24. V.A. Bovda et al. Magnetic field losses in Nd$\mathrm{Fe}-\mathrm{B}$ magnets under $10 \mathrm{MeV}$ electron irradiation // Problems of Atomic Science and Technology. Series "Nuclear Physics Investigations" (109). 2017, N 3, p. 90-94.

25. A.M. Bovda et al. Magnetic properties of Sm2Co17 magnets under $10 \mathrm{MeV}$ electron beam // Problems of Atomic Science and Technology. Series "Nuclear Physics Investigations" (112). 2017, N 6, p. 162-166.
26. V.A. Bovda, A.M. Bovda, I.S. Guk. A.N. Dovbnya, S.G. Kononenko, V.N. Lyashchenko, A.O. Mytsykov, L.V. Onischenko. Dipole Magnet With A Permanent Magnetic Field For Technological Electron Accelerator // Proceedings of the REPM 2016, Darmstadt, Germany, 28 August - 1 September 2016, p. 481-487.

27. M.I. Ayzatskiy et al. The NSC KIPT electron linacs - R\&D // Problems of Atomic Science and Technology. Series "Nuclear Physics Investigations". 2003, N 2(33), p. 19-25.

\section{ИСПОЛЬЗОВАНИЕ РЕДКОЗЕМЕЛЬНЫХ ПОСТОЯННЫХ МАГНИТОВ В МАГНИТНОЙ СИСТЕМЕ ЭЛЕКТРОННОГО УСКОРИТЕЛЯ НА ЭНЕРГИЮ 10 МЭВ}

В.А. Бовда, А.М. Бовда, И.С. Гук, С.С. Кандыбей, С.Г. Кононенко, В.Н. Лященко, А.О. Мыцыков, Л.В. Онищенко

Экспериментально исследована радиационная стойкость магнитных материалов из Sm-Co- и $\mathrm{Nd}-\mathrm{Fe}-\mathrm{B}-$ сплавов под действием 10 МэВ электронного пучка. На основе образцов из $\mathrm{Sm}_{2} \mathrm{Co}_{17}$-сплава размерами 30x24x12 мм проведено моделирование и конструирование магнита для анализа пучка электронов технологического ускорителя на энергию 10 МэВ. Приведены результаты экспериментального исследования характеристик магнита. Максимальное поле в магните равно 0,3 Тл.

\section{ВИКОРИСТАННЯ РІДКІСНОЗЕМЕЛЬНИХ ПОСТІЙНИХ МАГНІТІВ У МАГНІТНІЙ СИСТЕМІ ЕЛЕКТРОННОГО ПРИСКОРЮВАЧА НА ЕНЕРГІЮ 10 МеВ}

\section{В.О. Бовда, О.М. Бовда, І.С. Гук, С.С. Кандибей, С.Г. Кононенко, В.М. Лященко, А.О. Мициков, Л.В. Оніщенко}

Експериментально досліджена радіаційна стійкість магнітних матеріалів зі Sm-Co- i Nd-Fe-B-сплавів під дією 10 МэВ електронного пучка. На основі зразків зі $\mathrm{Sm}_{2} \mathrm{Co}_{17}$-сплаву розмірами $30 \times 24 \times 12$ мм проведені моделювання і конструювання магніту для аналізу пучка електронів технологічного прискорювача на енергію 10 МеВ. Приведено результати експериментального дослідження характеристик магніту. Максимальне поле в магніті дорівнює 0,3 Тл. 